\title{
Treating Arterial Stiffness Associated with Features of Metabolic Syndrome Not Included in its Diagnostic Criteria: Cutting Off the Heads of Lernaean Hydra, Keeper of the Underworld
}

\author{
Vasilios G. Athyros ${ }^{1}$, Alessandra Ferlita ${ }^{2}$, Konstantinos Tziomalos $^{3}$ and Manfredi Rizzo ${ }^{2,4, *}$
}

\begin{abstract}
${ }^{I}$ Second Propedeutic Department of Internal Medicine, Medical School, Aristotle University of Thessaloniki, Hippokration Hospital, Thessaloniki, Greece; ${ }^{2}$ Biomedical Department of Internal Medicine and Medical Specialties, University of Palermo, Italy; ${ }^{3}$ First Propedeutic Department of Internal Medicine, Medical School, Aristotle University of Thessaloniki, AHEPA Hospital, Thessaloniki, Greece; ${ }^{4}$ Euro-Mediterranean Institute of Science and Technology, Italy
\end{abstract}

\begin{abstract}
The clustering of cardio-metabolic risk factors, regardless if this is called metabolic syndrome (MetS) or not, substantially increases the risk of cardiovascular disease (CVD) and all-cause mortality. One of the possible mechanisms of the rise in CVD incidence is the increase in arterial stiffness (AS), which is a significant and independent CVD risk factor. Hypertension has long been connected to AS. Besides MetS components (obesity, dyslipidaemia, hypertension, dysglycaemia), MetS-associated disease states, not included in the MetS diagnostic criteria (renal dysfunction, hyperuricaemia, non alcoholic fatty liver disease, obstructive sleep apnea, polycystic ovary syndrome and hypercoaglutability) have been implicated in the increase of CVD risk through the increase of AS, among other mechanisms. Treatment options for AS induced by these non-diagnostic features of MetS are discussed. The impact of lifestyle changes is analyzed. Among pharmacological interventions, statin treatment seams to hold a pivotal role. Furthermore, we discuss specific measures for each disease state separately.
\end{abstract}

Keywords: Metabolic syndrome, arterial stiffness, hypertension, cardiovascular disease, chronic kidney disease, hyperuricaemia, non alcoholic fatty liver disease, obstructive sleep apnea, polycystic ovary syndrome.

\section{INTRODUCTION}

The metabolic syndrome (MetS) is a cluster of cardiovascular disease (CVD) and type 2 diabetes mellitus (T2DM) risk factors [1], that increases the risk of CVD events [2,3] and all-cause mortality [4], even in the absence of clinically evident CVD and/or T2DM [5,6]. MetS, also called "insulin resistance syndrome", "deadly quartet" or "syndrome X", is becoming a worldwide epidemic. According to definition used, $32-40 \%$ of the adult population of developed countries have MetS, as a result of the increasing prevalence of obesity and sedentary lifestyle [7]. However, it has been suggested that when confounding factors such as obesity are taken into account, MetS has a negligible association with CVD risk [8]. This led the American Diabetes Association and the European Association for the Study of Diabetes to issue a joint statement expressing concerns on the clinical utility of MetS as a syndrome [9]. However, it is widely accepted that the clustering of several CVD risk factors, regardless if they are considered as a syndrome or not, confer an increased CVD risk, even if this is the equal to the sum of the risks conferred by the individual MetS components. The International Diabetes Federation [http://www.idf.org/ webdata/docs/IDF Meta def_final.Pdf] released a worldwide definition of MetS with the following criteria: central obesity

*Address correspondence to this author at the Biomedical Department of Internal Medicine and Medical Specialties, University of Palermo, Via del Vespro, 141, 90127, Palermo, Italy; Tel: +39(091)6552945;

Fax:+39(091)6552945; Email: manfredi.rizzo@unipa.it [defined as increased waist circumference using ethnicityspecific values] plus any 2 of the following features: raised triglycerides (TG) $(>150 \mathrm{mg} / \mathrm{dL})$ or specific treatment for this lipid abnormality, reduced high-density lipoprotein cholesterol (HDL-C) levels $(<40 \mathrm{mg} / \mathrm{dL}$ in males and $<50$ $\mathrm{mg} / \mathrm{dL}$ in females) or specific treatment for this lipid abnormality, raised blood pressure (BP) (systolic BP $>130 \mathrm{mmHg}$ or diastolic $\mathrm{BP}>85 \mathrm{mmHg}$ ) or treatment for hypertension, and raised fasting plasma glucose (FPG) levels $(>100$ $\mathrm{mg} / \mathrm{dL}$ ) or previously diagnosed T2DM. In this consensus definition, obesity is characterised as the main clinical manifestation of MetS and insulin resistance (IR) as the central pathophysiological abnormality. However, there are other CVD risk factors associated with MetS which are not included in the diagnostic criteria of MetS. These include chronic kidney disease (CKD), elevated serum uric acid (SUA) levels, non-alcoholic fatty liver disease (NAFLD), lipid (mainly low-density (LDL)) particle abnormalities, prothrombotic factors, cytokines, adipokines, vitamin D, polycystic ovary syndrome (PCOS), and obstructive sleep apnea (OSA).

MetS is related to arterial stiffness (AS) at a population level [10-12], even in patients without hypertension or T2DM [13]. AS and its haemodynamic consequences have been established as predictors of adverse CVD outcomes $[14,15]$. AS is closely related to systolic hypertension and has a causal association with coronary artery disease (CAD), stroke, and heart failure (HF), which are the leading causes of morbidity and mortality in western countries [15-17]. Al- 
though elevated BP is a major determinant of AS, the latter has incremental predictive value over and above that of brachial BP, and may be induced by CVD risk factors other than hypertension [17]. Part of the CVD risk associated by MetS could be driven by the increase in AS.

The question is: do the features of MetS not included in its diagnostic criteria increase AS and consequently CVD risk? Because if they do, they should be diagnosed, monitored, and treated to reduce the total CVD risk related to MetS.

\section{PATHOPHYSIOLOGY OF AS}

Arterial compliance plays a key role in the function of the cardiovascular system, given the intermittent contraction of left ventricle (LV) in contrast to the continuous need of organs and tissues for oxygen and nutrients supply [14]. The contraction of the LV increases the pressure in large vessels (i.e. aorta), which, because of their elasticity, store a significant part of the blood ejected from LV contraction. After the closure of the aortic valve, the recoil of large vessels during LV diastole drives the blood towards the periphery, maintaining a continuous flow to organs and tissues [14].

The elastic properties of arteries differ along the arterial tree, proximal arteries being more elastic and distal arteries being stiffer [18]. AS is largely determined by the structure of the tunica media, which contains the elastic components of the aortic wall, i.e. elastin fibers and collagen [19]. Several factors influence arterial wall structure and elasticity. Ageing is closely associated with AS through the fragmentation of elastin fibers, the decrease in elastin/collagen ratio and the calcification of the tunica media [19]. This process is called arteriosclerosis and should be distinguished from atherosclerosis, which is a disease of the tunica intima. Hypertension is a major determinant of arteriosclerosis and AS, through changes in the tunica media that take place earlier than that induced by ageing, a condition coined "early vascular ageing". Moreover, AS results in further worsening of hypertension forming a vicious cycle [19]. However, AS is also caused by other CVD risk factors besides hypertension, including smoking, T2DM, hypercholesterolaemia and CKD $[16,20,21]$. AS is characterized by increased pulse wave velocity (PWV) and early return in the ascending aorta of reflected waves, i.e. during the systolic phase of the pressure waveform. Thus, systolic central aortic blood pressure (CABP), and consequently LV afterload, is increased. These changes induce LV hypertrophy (and stiffness) and predispose to LV systolic and (mainly) diastolic dysfunction [19]. Furthermore, in patients with AS, CABP during the diastole is decreased, thus substantially reducing diastolic myocardial perfusion. The combination of LV hypertrophy and reduced coronary perfusion leads to myocardial oxygen supply/demand mismatch, and further deteriorates LV systolic and diastolic function [22]. This combination of high systolic and low diastolic CABP leads to increased pulse pressure (PP), which reflects AS and appears to represent the predictive marker most closely related with CVD risk in hypertensive patients [22].

\section{AS IN METS-ASSOCIATED CKD}

Patients with MetS have an up to 5 times increased risk for developing CKD in comparison with those without the syndrome $[23,24]$. A meta-analysis of 11 studies $(n=30,146)$ showed that MetS is causally associated with the development of $\mathrm{CKD}$, defined as estimated glomerular filtration rate (eGFR) $<60 \mathrm{ml} / \mathrm{min}$ per $1.73 \mathrm{~m}^{2}$ (CKD stage 3 or higher) and/or microalbuminuria or overt proteinuria [23]. In turn, patients with CKD are at an increased risk not only for endstage renal disease (ESRD), but also for CVD [25]. CKD is a CVD predictor and is practically considered as a CAD equivalent, similar to T2DM [26-31]. A major CKD risk factor is increased AS of large arteries, which is independent of other major risk factors for AS [26]. In addition, increased AS of central arteries may cause further reduction in eGFR in patients with CKD resulting in a vicious cycle [32]. This suggests that CKD may interact not only with small but also with large arteries AS, independently of age, BP and other established CVD risk factors [32,33]. On the other hand, AS is an independent predictor of survival in the general population [34]. Given that some statins play a role in improvement of renal function and in arterial "destiffening" [27-31,35,36], it has been suggested that the statin dose and the specific compound play a major role in achieving improvement of GFR and reduction of AS and CVD risk [37]. Indeed, statins have been shown to substantially reduce AS in patients with CKD [38]. Moreover, statins (mainly atorvastatin) are implicated in improvement of renal function and thus, among others, they reduce CKD-related AS and CVD risk in patients with MetS. The Heart Protection Study (HPS) showed that allocation to simvastatin significantly attenuated the fall in eGFR in both diabetic and non-diabetic patients compared with placebo [39]. A pooled analysis of the Cholesterol And Recurrent Events (CARE), Long-term Intervention with Pravastatin in Ischemic Disease (LIPID) and West Of Scotland Coronary Prevention Study (WOSCOPS) trials comparing pravastatin with placebo also showed a decreased deterioration of renal function in patients treated with pravastatin [40]. In the Greek atorvastatin and coronary heart disease evaluation (GREACE) study, atorvastatin treatment significantly increased eGFR and reduced SUA levels, whereas renal function deteriorated in untreated patients [28-31]. In GREACE $[28,41]$ as well as in the IMproving the imPlemEntation of cuRrent guidelines for the mAnagement of major coronary hearT disease rIsk factors by multifactorial interVEntion (IMPERATIVE) study [30] and in the Assessing the Treatment Effect in Metabolic Syndrome Without Perceptible Diabetes (ATTEMPT) study [31], the effect of atorvastatin on renal function was rapid, more evident in patients with serum creatinine levels at the upper end of the reference range, more pronounced at higher doses and independently contributed to the reduction in CVD events [28]. A post hoc analysis of the Treating to New Targets (TNT) trial showed that instead of the expected decline of about 5 $\mathrm{ml} / \mathrm{min}$ over the 5 years study period, there was a significant increase in eGFR in patients treated with atorvastatin 10 $\mathrm{mg} /$ day (by $5.6 \%$ ) and $80 \mathrm{mg} /$ day (by $8.4 \%$ ) [42]. In patients with CKD, atorvastatin $80 \mathrm{mg} /$ day induced a relative reduction in CVD events by $32 \%$ compared with $10 \mathrm{mg} / \mathrm{day}$, whereas in patients with normal kidney function the relative CVD risk reduction with the higher atorvastatin dose was $15 \%(p<0.01)$ [42]. Thus, the effect of statins on renal function may depend on the specific statin used, the degree of lipid-lowering and the renal function. These factors need to be considered in statin treatment. Given that CKD and CAD 
may progress in parallel, and one of the links might be AS, appropriate statin treatment at an appropriate dose may be beneficial to both the heart and kidneys, partly through improving AS.

\section{AS IN METS-ASSOCIATED HYPERURICAEMIA}

Elevated SUA levels are related to CKD and the presence of MetS [43] and further rise as the MetS components (hypertension, dyslipidaemia, DM and visceral obesity) increase [44]. Accordingly, several researchers suggested that SUA should be considered as a MetS component [45]. Elevated SUA levels are also closely related to CKD and are associated with increased CVD morbidity and mortality, at least in high-risk patients [46]. SUA appears to be significantly correlated with central systolic BP and AS in both genders [47]. Therefore, SUA may contribute to the pathogenesis of hypertension, mainly through increased wave reflections and thus contribute to the increase in CVD risk [47]. Indeed, in both genders, SUA levels are associated with AS, and this relationship is independent of other conventional risk factors for MetS and CVD [48,49]. In contrast, a study that included relatively young men and women suggested that SUA levels are associated with an increase in AS, but women appeared to be more susceptible to vascular damage associated with high SUA levels [50]. More specifically, subjects with hyperuricaemia had significantly elevated carotid-ankle PWV in both genders, but the carotid-femoral PWV was increased only in women [50]. Interestingly, in a recent study in subjects with SUA levels within the reference range, those with high-normal SUA levels had an increased AS (higher brachial-ankle PWV) after adjusting for confounding factors [51]. Thus, even SUA levels within the normal range appear to represent a risk factor for AS [51].

\section{AS IN METS-ASSOCIATED NAFLD}

NAFLD is the most common form of chronic liver disease. It affects $20-35 \%$ of the general population in developed countries and its prevalence reaches $70-90 \%$ in subjects with obesity, MetS or T2DM [52]. NAFLD is considered the hepatic manifestation of MetS, since it is closely related to other clinical features of MetS [53,54]. Interestingly, AS appears to be independently associated with NAFLD $[53,54]$. Moreover, the results of a large study $(n=4,467)$ suggested that not only the presence but also the severity of NAFLD are associated with AS in non-hypertensive, nondiabetic subjects with or without MetS [55]. Regarding NAFLD treatment, there is no widely accepted therapy. However, recent data suggest that statins are not only safe in patients with NAFLD but also exert beneficial effects on CVD risk and may cause NAFLD resolution. The GREACE Study $(n=1,600)$ included patients with overt CAD randomised into 2 groups: the usual care group, treated by physicians chosen by patients and the structured care group, treated similarly with those in usual care plus atorvastatin titrated to achieve LDL cholesterol (LDL-C) levels $<100$ $\mathrm{mg} / \mathrm{dl}$ [56]. In a post hoc analysis of GREACE, 227 patients with NAFLD at baseline were treated with atorvastatin and 210 were not treated with a statin [56]. Those treated with atorvastatin for 3 years showed resolution of NAFLD, as demonstrated by resolution of fatty liver in ultrasonography and normalization of serum transaminases levels [56]. Moreover, atorvastatin reduced CVD morbidity and mortality in NAFLD patients more than in those without NAFLD (68 vs 39\%, respectively; $p=0.007$ ) [56]. Therefore, 3 benefits of statins were observed in patients with NAFLD in GREACE: resolution of NAFLD, significant CVD reduction and safety. Similar benefits of statins were observed in ATTEMPT, a primary prevention study in patients with MetS [57]. In a very recent preliminary report involving 6 patients with biopsy-proven non-alcoholic steatohepatitis treated with rosuvastatin (10 $\mathrm{mg} /$ day), liver enzymes gradually improved by the 3rd month and returned to normal by the end of 1 year. There was a complete resolution of non-alcoholic steatohepatitis in the second biopsy in all patients [58]. The estimated CVD risk status was also lowered after treatment [58].

\section{AS IN METS-ASSOCIATED ATHEROGENIC DYSLIPIDAEMIA}

Atherogenic dyslipidaemia (low HDL-C levels and/or high TG is a MetS component and is outside of the scope of the present review. However, dyslipidaemia in MetS is also characterized by the predominance of small dense LDL (sdLDL) particles [59]. sdLDL represents an emerging CVD risk factor, since these particles can be associated with CVD independently of established risk factors, including plasma lipids [59]. It has been shown that subjects with high levels of sdLDL particles have an approximately 3- to 7-fold increased risk of developing CAD, independently of LDL-C concentration [60]. This predominance of sdLDL particles is associated with raised TG and decreased HDL-C levels, forming the so-called "atherogenic lipid triad" [61-63]. Adipose tissue also produces a diversity of adipokines that play a role in the pathogenesis of inflammation, dyslipidaemia and hypertension [64] that increase CVD morbidity and mortality linked to obesity, T2DM and MetS [65]. sdLDL also represents a marker of MetS severity $[66,67]$. In this context, we confirmed that sdLDL are increased in the MetS and showed an independent predictive role for future CVD and cerebrovascular events $[66,67]$. Moreover, MetS patients with hypercholesterolaemia have a higher central pulse pressure and stiffer blood vessels than matched controls, despite similar peripheral BP [68]. Elevated LDL-C levels, which are not included in the MetS diagnostic criteria, appear to be independently associated with AS, while HDL-C is inversely associated with AS [69]. It has also been shown that PWV, and therefore AS, is increased in carriers of the lecithin cholesterol acetyl-transferase mutation related to low HDL-C levels [70]. The TG/HDL-C ratio, a rough measure of the predominance of sdLDL particles over large-buoyant ones [71], is an independent determinant of AS in older adults, younger adults and adolescents, particularly in those with central obesity, regardless of the presence of hypertension $[69,72,73]$. The treatment of choice for elevated sdLDL is statins because, beside the preferential reduction in sdLDL particles, they reduce markers of inflammation such as lipoprotein-associated phospholipase A2 (Lp-PLA2) [74-77]. Ezetimibe decreases the large and medium LDL particles and, to a lesser extent, the sdLDL particles, while it has no influence on LDL size; however, its sdLDL-lowering capacity may be enhanced in individuals with elevated TG levels 
[78]. Thus, statin treatment reduces LDL mass, increases LDL particle size and reduces AS related to the "atherogenic lipid triad".

\section{AS IN METS-ASSOCIATED OBSTRUCTIVE SLEEP APNEA (OSA)}

About 24\% of men aged 30-60 years and 9\% of adult women are estimated to have OSA and most of these patients also have MetS [79]. The independent association of overweight/obesity-associated OSA with CVD morbidity and mortality consists a major health problem [80]. Data indicate a causal relationship between overweight/obesity, hypertension, T2DM, CVD and OSA, while the relative risk for allcause mortality in patients with OSA is 1.5 compared with those without OSA [80]. One of the possible mechanisms for these sequelae of OSA is increased AS [79,81]. It has been shown that the severity of OSA correlates with the severity of MetS and AS in obese patients [82]. Moreover, even short-term weight loss improves not only metabolic dysfunction but also the severity of OSA and AS [82]. Interventional studies showed a substantial improvement in symptoms associated with OSA (daytime sleepiness, snoring, morning headaches) as well as a reduction in BP in patients receiving continuous positive airway pressure therapy (CPAP) $[79,80]$. Moreover, the benefits of CPAP on reduction of fatal and nonfatal CVD events have been established in multiple large trials [82]. It has also been clearly shown that after CPAP treatment in patients with OSA there was a significant improvement in all indices of AS [79,83-86].

\section{AS IN POSTMENOPAUSAL WOMEN WITH METS}

Postmenopausal women have a higher prevalence of MetS, because of hormonal and metabolic changes, which in turn are also related to increased AS [37-39]. A study evaluated the independent and combined effects of hypocaloric diet and low-intensity resistance exercise training on PWV and body composition in obese postmenopausal women [88]. The hypocaloric diet decreased PWV and this reduction was related to the loss of body fat. Although low-intensity resistance exercise training alone did not affect PWV or body composition, its combination with hypocaloric diet improved PWV and muscle strength, while preventing loss of lean body mass in postmenopausal women with MetS [88]. A cross-sectional study in 385 postmenopausal women aged 50-74 years from the general population reported increased AS [89]. Estimated 10-year risk for CAD, stroke and death rose with increasing AS in a linear graded manner [89]. In another study in 9,555 postmenopausal women, 455 had MetS with normal BP and glucose levels, mean age, body mass index (BMI), waist circumference, FPG, TG, systolic and diastolic BP, aortic and peripheral PWV increased, while HDL-C and adiponectin levels decreased according to the degree of IR, assessed with homeostatic model assessment of IR (HOMA-IR) [87]. Age, BMI, FPG, TG, insulin, systolic BP, HOMA-IR, aortic and peripheral PWV were higher in women with central obesity, while HDL-C and adiponectin were lower [87]. PWV (aortic and peripheral) correlated with age, waist circumference, total cholesterol, systolic and diastolic BP, insulin, and HOMA-IR. In addition, systolic and diastolic BP and HOMA-IR independently correlated with PWV [87]. It has been suggested that low-dose emidrate estradiol/drospirenone vs low-dose emidrate estradiol/ dydrogesterone combination might be an option to manage MetS features, particularly impaired glucose metabolism [90]. Both combinations induced a decline in FPG levels but only drospirenone exerted positive effects on FPG levels and IR, induced favourable changes in the lipid profile and reduced inflammatory indices in postmenopausal women with MetS [90]. These effects might also positively affect AS. Finally, the association between MetS and AS was also observed in premenopausal women with multiple cardiometabolic risk factors suggesting that obesity might play a key role in the pathogenesis of AS [91].

\section{AS IN METS-ASSOCIATED PCOS}

Patients with PCOS have a higher prevalence of IR and MetS, increased AS, and display subclinical evidence of early CVD disease [92]. Similarly, young lean women with PCOS exhibit increased AS, even in the absence of established CVD risk factors, such as hypertension and obesity [93]. In patients with IR due to PCOS, metformin improved aortic and brachial PWV, CABP and endothelial function $[92,94]$. Metformin also reduced weight, waist circumference and TG and increased adiponectin levels [92]. It has been also demonstrated that there is an improvement in the elastic parameters of the aorta by adding metformin to oral contraceptive pill [94]. We suggest that metformin treatment might decrease CVD risk in women with PCOS [94].

\section{AS IN METS-ASSOCIATED HYPERCOAGULA- BILITY}

In patients with MetS, metabolic abnormalities (in glucose and lipid metabolism) and haemodynamic abnormalities (renin-angiotensin-aldosterone system stimulation, sympathetic overactivity, decreased nitric oxide bioavailability) interact to result in anaemia, hypercoagulability, organ ischaemia, AS, hypertension and renal and LV dysfunction [95]. This constellation of abnormalities has been characterized as the "circulatory syndrome" as an attempt to expand the concept of MetS by adding recently documented CVD risk factors including renal impairment, microalbuminuria, $\mathrm{AS}, \mathrm{HF}$ with preserved ejection fraction (HFpEF), and anaemia to more established risk factors including hypertension, dyslipidemia and abnormal glucose metabolism $[95,96]$. Within or outside this "circulatory syndrome" frame, MetS is related with increased levels of clotting factors (tissue factor, FVII and fibrinogen) and with inhibition of endogenous fibrinolysis (increased plasminogen activator inhibitor-1 levels and decreased tissue plasminogen activator activity) [96,97]. Fibrinogen levels correlate with lipid [98] and inflammatory parameters [96,98], suggesting an involvement of adipose tissue-generated proinflammatory cytokines [96]. Elevated von Willebrand factor and FVIII levels are associated with endothelial injury, whereas vitamin K-dependent coagulation factors correlate with TG levels [60]. All these abnormalities seem to inter-relate with lowgrade inflammation and AS [95, 96]. Moreover, low adiponectin levels are associated with the simultaneous presence of CKD, anaemia, AS and hypercoagulability [99]. It has been shown that thiazolidinediones increase the secretion of high molecular weight adiponectin from adipocytes [100]. Similarly to all other risk factors associated with MetS, first 
line therapy for hypercoagulability should include lifestyle changes, i.e. diet and increased physical activity. The adoption of a physically active lifestyle is independently associated with lower levels of inflammation and coagulation markers in patients with MetS [101]. The latter may suggest a pathway for reducing CVD events in all these patients and particularly in those at higher CVD risk [101].

\section{CONCLUSIONS}

AS is an important and independent CVD risk factor. A cluster of abnormalities related to MetS that are either included in its diagnostic criteria (obesity, hypertension, dyslipidaemia, dysglycaemia) or not (renal dysfunction, hyperuricaemia, hypercoaglutability, NAFLD, OSA, PCOS) synergistically contribute to the increase of AS and thus to excessive CVD risk. Lifestyle changes and antihypertensive, hypolipidaemic and antidiabetic agents, as well as CPAP in patients with OSA, substantially contribute to the reduction of AS and finally to the decrease in CVD risk. However, there is a great unmet need for well-planned, prospective, randomized, controlled and long-term interventional trials to assess the clinical benefits of regimens that improve AS. Multifactorial intervention that reduces CVD risk [102,103] might be even more beneficial and should also be evaluated.

\section{CONFLICT OF INTEREST}

This review was written independently; no company or institution supported the authors financially or by providing a professional writer. Some of the authors have given talks, attended conferences and participated in trials and advisory boards sponsored by various pharmaceutical companies in the past, but they have no conflict of interest.

\section{ACKNOWLEDGEMENT}

Declared none.

\section{ABBREVIATION LIST}

$\begin{array}{ll}\mathrm{AS} & =\text { Arterial stiffness } \\ \mathrm{BP} & =\text { Blood pressure } \\ \mathrm{CABP} & =\text { Central aortic blood pressure } \\ \mathrm{CAD} & =\text { Chronic kidney disease } \\ \mathrm{CKD} & =\text { Continuous positive airway pressure therapy } \\ \mathrm{CPAP} & \text { GREek Atorvastatin and Coronary heart dis- } \\ \text { GREACE } & \text { ease Evaluation study } \\ \mathrm{CVD} & =\text { Estimated glomerular filtration rate } \\ \text { eGFR } & =\text { End stage renal disease } \\ \mathrm{ESRD} & =\text { Fasting plasma glucose } \\ \text { FPG } & =\text { High density lipoprotein cholesterol } \\ \mathrm{HDL}-\mathrm{C} & \text { Heart failure } \\ \mathrm{HF} & \text { Homeostatic model assessment } \\ \mathrm{HOMA} & =\text { Insulin resistance }\end{array}$

$\begin{array}{ll}\text { LDL-C } & \text { Low-density lipoprotein cholesterol } \\ \text { LV } & =\text { Left ventricle } \\ \text { Lp-PLA2 } & \text { Lipoprotein-associated phospholipase A2 } \\ \text { MetS } & =\text { Metabolic syndrome } \\ \text { NAFLD } & =\text { Non-alcoholic fatty liver disease } \\ \text { OSA } & =\text { Obstructive sleep apnea } \\ \text { PCOS } & =\text { Polycystic ovary syndrome } \\ \text { PWV } & =\text { Pulse wave velocity } \\ \text { sdLDL } & =\text { Small dense low-density lipoprotein } \\ \text { SUA } & =\text { Serum uric acid } \\ \text { TG } & =\text { Triglycerides } \\ \text { T2DM } & =\text { Type } 2 \text { diabetes mellitus }\end{array}$

\section{REFERENCES}

[1] Expert Panel on Detection Evaluation, and Treatment of High Blood Cholesterol in Adults, Executive Summary of the Third Report of the National Cholesterol Education Program (NCEP) Expert Panel on Detection, Evaluation, and Treatment of High Blood Cholesterol in Adults (Adult Treatment Panel III). JAMA 2001; 285: 2486-97.

[2] Alberti KG, Zimmet P, Shaw J; Group, IETFC. The metabolic syndrome-a new worldwide definition. Lancet 2005; 366: 1059-62.

[3] Alberti KG, Eckel RH, Grundy SM, et al; International Diabetes Federation Task Force on Epidemiology and Prevention; National Heart, Lung, and Blood Institute; American Heart Association; World Heart Federation; International Atherosclerosis Society; International Association for the Study of Obesity. Harmonizing the metabolic syndrome: a joint interim statement of the International Diabetes Federation Task Force on Epidemiology and Prevention; National Heart, Lung, and Blood Institute; American Heart Association; World Heart Federation; International Atherosclerosis Society; and International Association for the Study of Obesity. Circulation 2009; 120: 1640-5.

[4] Isomaa B, Almgren P, Tuomi T, et al. Cardiovascular morbidity and mortality associated with the metabolic syndrome. Diabetes Care 2001; 24: 683-9.

[5] Lakka HM, Laaksonen DE, Lakka TA, et al. The metabolic syndrome and total and cardiovascular disease mortality in middleaged men. JAMA 2002; 288: 2709-16.

[6] Ford ES. The metabolic syndrome and mortality from cardiovascular disease and all-causes: findings from the National Health and Nutrition Examination Survey II Mortality Study. Atherosclerosis 2004; 173: 309-14.

[7] Corrado E, Rizzo M, Caccamo G, et al. Prevalence of metabolic syndrome: a comparative analysis in an unselected sample of Mediterranean subjects. Int Angiol 2012; 31: 572-8.

[8] Kahn R. Metabolic syndrome-what is the clinical usefulness? Lancet 2008; 371: 1892-3.

[9] Kahn R, Buse J, Ferrannini E, Stern M; American Diabetes Association; European Association for the Study of Diabetes. The metabolic syndrome: time for a critical appraisal: joint statement from the American Diabetes Association and the European Association for the Study of Diabetes. Diabetes Care 2005; 28: 2289-304.

[10] Li CI, Kardia SL, Liu CS, et al. Metabolic syndrome is associated with change in subclinical arterial stiffness: a community-based Taichung community health study. BMC Public Health 2011; 11: 808-15.

[11] Nakanishi N, Suzuki K, Tatara K. Clustered features of the metabolic syndrome and the risk for increased aortic pulse wave velocity in middle-aged Japanese men. Angiology 2003; 54: 551-9.

[12] Choi KM, Lee KW, Seo JA, et al. Relationship between brachialankle pulse wave velocity and cardiovascular risk factors of the metabolic syndrome. Diabetes Res Clin Pract 2004; 66: 57-61.

[13] Sengstock DM, Vaitkevicius PV, Supiano MA. Arterial stiffness is related to insulin resistance in nondiabetic hypertensive older adults. J Clin Endocrinol Metab 2005; 90: 2823-7. 
[14] Laurent S, Alivon M, Beaussier H, Boutouyrie P. Aortic stiffness as a tissue biomarker for predicting future cardiovascular events in asymptomatic hypertensive subjects. Ann Med 2012; 44 (Suppl 1): S93-7.

[15] Palatini P, Casiglia E, Gąsowski J, et al. Arterial stiffness, central hemodynamics, and cardiovascular risk in hypertension. Vasc Health Risk Manag 2011; 7: 725-39.

[16] Boutouyrie P, Tropeano AI, Asmar R, et al. Aortic stiffness is an independent predictor of primary coronary events in hypertensive patients: a longitudinal study. Hypertension 2002; 39: 10-5.

[17] Vlachopoulos C, Aznaouridis K, O'Rourke MF, Safar ME, Baou K, Stefanadis, C. Prediction of cardiovascular events and all-cause mortality with central haemodynamics: a systematic review and meta-analysis. Eur Heart J 2010; 31: 1865-71.

[18] Antonini-Canterin F, Carerj S, Di Bello V, et al; Research Group of the Italian Society of Cardiovascular Echography (SIEC). Arterial stiffness and ventricular stiffness: a couple of diseases or a coupling disease? A review from the cardiologist's point of view. Eur J Echocardiogr 2009; 10: 36-43.

[19] Vlachopoulos C, Alexopoulos N, Stefanadis C. Aortic stiffness: prime time for integration into clinical practice? Hellenic J Cardiol 2010; 51: 385-90.

[20] Sassalos K, Vlachopoulos C, Alexopoulos N, Gialernios T, Aznaouridis K, Stefanadis C. The acute and chronic effect of cigarette smoking on the elastic properties of the ascending aorta in healthy male subjects. Hellenic J Cardiol 2006; 47: 263-8.

[21] Cruickshank K, Riste L, Anderson SG, Wright JS, Dunn G, Gosling RG. Aortic pulse-wave velocity and its relationship to mortality in diabetes and glucose intolerance: an integrated index of vascular function? Circulation 2002; 106: 2085-90.

[22] Vlachopoulos C, O'rourke M. Genesis of the normal and abnormal arterial pulse. Curr Probl Cardiol 2000; 25: 303-67.

[23] Thomas G, Sehgal AR, Kashyap SR, Srinivas TR, Kirwan JP, Navaneethan SD. Metabolic syndrome and kidney disease: a systematic review and meta-analysis. Clin J Am Soc Nephrol 2011; 6: 2364-73.

[24] Katsiki N, Athyros VG, Karagiannis A, Mikhailidis DP. Characteristics Other Than the Diagnostic Criteria Associated with Metabolic Syndrome: an Overview. Curr Vasc Pharmacol 2013 Apr 25. [Epub ahead of print]

[25] Weir MR. Recognizing the link between chronic kidney disease and cardiovascular disease. Am J Manag Care 2011; 17 (Suppl 15): S396-402.

[26] Shoji T, Abe T, Matsuo H, Egusa G, Yamasaki Y, Kashihara N, Shirai K, Kashiwagi A; Committee of Renal and Peripheral Arteries, Japan Atherosclerosis Society. Chronic kidney disease, dyslipidaemia, and atherosclerosis. J Atheroscler Thromb 2012; 19: 299315.

[27] Athyros VG, Mikhailidis DP, Liberopoulos EN, et al., Effect of statin treatment on renal function and serum uric acid levels and their relation to vascular events in patients with coronary heart disease and metabolic syndrome: a subgroup analysis of the GREek Atorvastatin and Coronary heart disease Evaluation (GREACE) Study. Nephrol Dial Transplant 2007; 22: 118-27.

[28] Athyros VG, Mikhailidis DP, Papageorgiou AA, et al. The effect of statins versus untreated dyslipidaemia on renal function in patients with coronary heart disease. A subgroup analysis of the Greek atorvastatin and coronary heart disease evaluation (GREACE) study. J Clin Pathol 2004; 57: 728-34.

[29] Athyros VG, Karagiannis A, Katsiki N, Mikhailidis DP. Statins in patients with renal dysfunction. Am J Cardiol 2012; 109: 1537.

[30] Athyros VG, Hatzitolios AI, Karagiannis A, et al. IMproving the imPlemEntation of cuRrent guidelines for the mAnagement of major coronary hearT disease rIsk factors by multifactorial interVEntion. The IMPERATIVE renal analysis. Arch Med Sci 2011; 7: 984-92.

[31] Athyros VG, Karagiannis A, Ganotakis ES, et al; Assessing The Treatment Effect in Metabolic syndrome without Perceptible diabeTes (ATTEMPT) Collaborative Group. Association between the changes in renal function and serum uric acid levels during multifactorial intervention and clinical outcome in patients with metabolic syndrome. A post hoc analysis of the ATTEMPT study. Curr Med Res Opin 2011; 27: 1659-68.

[32] Safar ME, London GM, Plante GE. Arterial stiffness and kidney function. Hypertension 2004; 43: 163-8.
[33] Katsiki N, Koumaras C, Athyros VG, Karagiannis A. Thinking beyond traditional cardiovascular risk factors: the role of arterial stiffness in targeting residual risk. Angiology 2012; 63: 9-11.

[34] Koumaras C, Tzimou M, Stavrinou E, et al. Role of antihypertensive drugs in arterial 'de-stiffening' and central pulsatile hemodynamics. Am J Cardiovasc Drugs 2012; 12: 143-56.

[35] Kanaki AI, Sarafidis PA, Georgianos PI, Kanavos K, Tziolas IM, Zebekakis PE, Lasaridis AN. Effects of low-dose atorvastatin on arterial stiffness and central aortic pressure augmentation in patients with hypertension and hypercholesterolemia. Am J Hypertens 2013; 26: 608-16.

[36] Sadat U, Howarth SP, Usman A, et al. Effect of low-and high-dose atorvastatin on carotid artery distensibility using carotid magnetic resonance imaging -a post-hoc sub group analysis of ATHEROMA (Atorvastatin Therapy: Effects On Reduction Of Macrophage Activity) Study. J Atheroscler Thromb 2013; 20: 46-56.

[37] Athyros VG, Karagiannis A, Kakafika A, Elisaf M, Mikhailidis DP. Statins and renal function. Is the compound and dose making a difference? Nephrol Dial Transplant 2007; 22: 963-4.

[38] Fassett RG, Robertson IK, Ball MJ, Geraghty DP, Sharman JE, Coombes JS. Effects of atorvastatin on arterial stiffness in chronic kidney disease: a randomised controlled trial. J Atheroscler Thromb 2010; 17: 235-41.

[39] Collins R, Armitage J, Parish S, et al. MRC/BHF Heart Protection Study of cholesterol-lowering with simvastatin in 5963 people with diabetes: a randomised placebo-controlled trial. Lancet 2003; 361: 2005-16.

[40] Tonelli M, Isles C, Craven T, et al. Effect of pravastatin on rate of kidney function loss in people with or at risk for coronary disease. Circulation 2005; 112: 171-8.

[41] Athyros VG, Mikhailidis DP, Liberopoulos EN, et al. Effect of statin treatment on renal function and serum uric acid levels and their relation to vascular events in patients with coronary heart disease and metabolic syndrome: a subgroup analysis of the GREek Atorvastatin and Coronary heart disease Evaluation (GREACE) Study. Nephrol Dial Transplant 2007; 22: 118-27.

[42] Shepherd J, Kastelein JJ, Bittner V, et al; TNT (Treating to New Targets) Investigators. Intensive lipid lowering with atorvastatin in patients with coronary heart disease and chronic kidney disease: the TNT (Treating to New Targets) study. J Am Coll Cardiol 2008; 51: 1448-54.

[43] Rizzo M, Obradovic M, Labudovic-Borovic M, et al. Uric Acid Metabolism in Pre-Hypertension and The Metabolic Syndrome. Curr Vasc Pharmacol 2013 Apr 25 [Epub ahead of print]

[44] Katsiki N, Karagiannis A, Athyros VG, Mikhailidis DP. Hyperuricaemia: more than just a cause of gout? J Cardiovasc Med (Hagerstown) 2013; 14: 397-402.

[45] Tsouli SG, Liberopoulos EN, Mikhailidis DP, Athyros VG, Elisaf MS. Elevated serum uric acid levels in metabolic syndrome: an active component or an innocent bystander? Metabolism 2006; 55: 1293-301.

[46] Bickel C, Rupprecht H J, Blankenberg S, et al. Serum uric acid as an independent predictor of mortality in patients with angiographically proven coronary artery disease. Am J Cardiol 2002; 89: 12-7.

[47] Hsu PF, Chuang SY, Cheng HM, et al. Associations of serum uric acid levels with arterial wave reflections and central systolic blood pressure. Int J Cardiol 2013 Feb 27 pii: S0167-5273(13)00223-4.

[48] Ishizaka N, Ishizaka Y, Toda E, Hashimoto H, Nagai R, Yamakado M. Higher serum uric acid is associated with increased arterial stiffness in Japanese individuals. Atherosclerosis 2007; 192: 131-7.

[49] Park JS, Kang S, Ahn CW, Cha BS, Kim KR, Lee HC. Relationships between serum uric acid, adiponectin and arterial stiffness in postmenopausal women. Maturitas 2012; 73: 344-8.

[50] Bian S, Guo H, Ye P, Luo L, Wu H, Xiao W. Serum uric Acid level and diverse impacts on regional arterial stiffness and wave reflection. Iran J Public Health 2012; 41: 33-41.

[51] Shin JY, Lee HR, Shim JY. Significance of high-normal serum uric acid level as a risk factor for arterial stiffness in healthy Korean men. Vasc Med 2012; 17: 37-43.

[52] Angulo P. Nonalcoholic fatty liver disease. N Engl J Med 2002; 346: 1221-31.

[53] Lee YJ, Shim JY, Moon BS, et al. The relationship between arterial stiffness and nonalcoholic fatty liver disease. Dig Dis Sci 2012; 57: 196-203. 
[54] Salvi P, Ruffini R, Agnoletti D, et al. Increased arterial stiffness in nonalcoholic fatty liver disease: the Cardio-GOOSE study. J Hypertens 2010; 28: 1699-707.

[55] Kim BJ, Kim NH, Kim BS, Kang JH. The association between nonalcoholic fatty liver disease, metabolic syndrome and arterial stiffness in nondiabetic, nonhypertensive individuals. Cardiology 2012; 123: 54-61.

[56] Athyros VG, Tziomalos K, Gossios TD, et al; GREACE Study Collaborative Group. Safety and efficacy of long-term statin treatment for cardiovascular events in patients with coronary heart disease and abnormal liver tests in the Greek Atorvastatin and Coronary Heart Disease Evaluation (GREACE) Study: a post-hoc analysis. Lancet 2010; 376: 1916-22.

[57] Athyros VG, Giouleme O, Ganotakis ES, et al. Safety and impact on cardiovascular events of long-term multifactorial treatment in patients with metabolic syndrome and abnormal liver function tests: a post hoc analysis of the randomised ATTEMPT study. Arch Med Sci 2011; 7: 796-805.

[58] Kargiotis K, Katsiki N, Athyros VG, et al, Effect of rosuvastatin on non-alcoholic steatohepatitis in patients with metabolic syndrome and hypercholesterolaemia. A preliminary report. Curr Vasc Pharmacol 2013 [in press].

[59] Nikolic D, Katsiki N, Montalto G, Isenovic ER, Mikhailidis DP, Rizzo M. Lipoprotein subfractions in metabolic syndrome and obesity: clinical significance and therapeutic approaches. Nutrients 2013; 5: 928-48

[60] Mikhailidis DP, Elisaf M, Rizzo M, et al. "European panel on low density lipoprotein (LDL) subclasses": A statement on the pathophysiology, atherogenicity and clinical significance of LDL subclasses: Executive summary. Curr Vasc Pharmacol 2011; 9: 531-2.

[61] Rizzo M, Kotur-Stevuljevic J, Berneis K, et al. Atherogenic dyslipidemia and oxidative stress: A new look. Transl Res 2009; 153: 217-23.

[62] Rizzo M, Mikhailidis DP. There is more to predicting vascular disease than just established risk factors. Curr Pharm Des 2011; 17: 3608-10.

[63] Rizzo M, Rini GB, Berneis K. The clinical relevance of LDL size and subclasses modulation in patients with type-2 diabetes. Exp Clin Endocrinol Diabetes 2007; 115: 477-82.

[64] Athyros VG, Tziomalos K, Karagiannis A, Anagnostis P, Mikhailidis DP. Should adipokines be considered in the choice of the treatment of obesity-related health problems? Curr Drug Targets 2010; 11: 122-35.

[65] Athyros VG, Tziomalos K, Karagiannis A, Mikhailidis DP. Dyslipidaemia of obesity, metabolic syndrome and type 2 diabetes mellitus: The case for residual risk reduction after statin treatment. Open Cardiovasc Med J 2011; 5: 24-34.

[66] Rizzo M, Berneis K. Small, dense low-density-lipoproteins and the metabolic syndrome. Diabetes Metab Res Rev 2007; 23: 14-20.

[67] Rizzo M, Pernice V, Frasheri A, et al. Small, dense low-density lipoproteins (LDL) are predictors of cardio- and cerebro-vascular events in subjects with the metabolic syndrome. Clin Endocrinol (Oxf.) 2009; 70: 870-5.

[68] Wilkinson I, Cockcroft JR. Cholesterol, lipids and arterial stiffness. Adv Cardiol 2007; 44: 261-77.

[69] Wang F, Ye P, Luo L, et al. Association of serum lipids with arterial stiffness in a population-based study in Beijing. Eur J Clin Invest 2011; 41: 929-36.

[70] van den Bogaard B, Holleboom AG, Duivenvoorden R, et al. Patients with low HDL-cholesterol caused by mutations in LCAT have increased arterial stiffness. Atherosclerosis 2012; 225: 481-5.

[71] Urbina EM, Khoury PR, McCoy CE, Dolan LM, Daniels SR, Kimball TR. Triglyceride to HDL-C ratio and increased arterial stiffness in children, adolescents, and young adults. Pediatrics 2013; 131: e1082-90.

[72] Shimizu Y, Nakazato M, Sekita T, et al. Association of arterial stiffness and diabetes with triglycerides-to-HDL cholesterol ratio for Japanese men: The Nagasaki Islands Study. Atherosclerosis 2013; 228: 491-495.

[73] Weng C, Yuan H, Yang K, et al. Sex-Specific Association Between the Metabolic Syndrome and Arterial Stiffness in 8300 Subjects. Am J Med Sci 2013 Mar 14. [Epub ahead of print]

[74] Matsuo T, Iwade K, Hirata N, et al. Improvement of arterial stiffness by the antioxidant and anti-inflammatory effects of short-term statin therapy in patients with hypercholesterolemia. Heart Vessels 2005; 20: 8-12.
[75] Florentin M, Tselepis AD, Elisaf MS, Rizos CV, Mikhailidis DP, Liberopoulos EN. Effect of non-statin lipid lowering and antiobesity drugs on LDL subfractions in patients with mixed dyslipidaemia. Curr Vasc Pharmacol 2010; 8: 820-30.

[76] Tselepis AF, Rizzo M, Goudevenos IA. Therapeutic modulation of lipoprotein-associated phospholipase A2 (Lp-PLA2). Curr Pharm Des 2011; 17: 3656-61.

[77] Ikewaki K, Terao Y, Ozasa $\mathrm{H}$, et al. Effects of atorvastatin on nuclear magnetic resonance-defined lipoprotein subclasses and inflammatory markers in patients with hypercholesterolemia. J Atheroscler Thromb 2009; 16: 51-6.

[78] Gouni-Berthold I, Mikhailidis DP, Rizzo M. Clinical benefits of ezetimibe use: Is absence of proof, proof of absence? Expert Opin Pharmacother 2012; 13: 1985-8.

[79] Litvin A, Sukmarova Z, Elfimova E, et al. Effects of CPAP on "vascular" risk factors in patients with obstructive sleep apnea and arterial hypertension. Vasc Health Risk Manag 2013; 9: 229-35.

[80] Somers VK, White DP, Amin R, et al. Sleep apnea and cardiovascular disease: an American Heart Association/American College of Cardiology Foundation Scientific Statement from the American Heart Association Council for High Blood Pressure Research Professional Education Committee, Council on Clinical Cardiology, Stroke Council, and Council on Cardiovascular Nursing. J Am Coll Cardiol 2008; 52: 686-717.

[81] Jones A, Vennelle M, Connell M, et al. Arterial stiffness and endothelial function in obstructive sleep apnoea/hypopnoea syndrome. Sleep Med 2013; 14: 428-32.

[82] Iguchi A, Yamakage H, Tochiya M, et al. Effects of Weight Reduction Therapy on Obstructive Sleep Apnea Syndrome and Arterial Stiffness in Patients with Obesity and Metabolic Syndrome. J Atheroscler Thromb $2013 \mathrm{Jul}$ 25. [Epub ahead of print]

[83] Marin JM, Carrizo SJ, Vicente E, Agusti AG. Long-term cardiovascular outcomes in men with obstructive sleep apnoeahypopnoea with or without treatment with continuous positive airway pressure: an observational study. Lancet 2005; 365:1046-53.

[84] Buchner NJ, Quack I, Stegbauer J, Woznowski M, Kaufmann A, Rump LC. Treatment of obstructive sleep apnea reduces arterial stiffness. Sleep Breath 2012; 16: 123-33.

[85] Vlachantoni IT, Dikaiakou E, Antonopoulos CN, Stefanadis C, Daskalopoulou SS, Petridou ET. Effects of continuous positive airway pressure (CPAP) treatment for obstructive sleep apnea in arterial stiffness: a meta-analysis. Sleep Med Rev 2013; 17: 19-28.

[86] Kato M, Kumagai T, Naito R, et al. Change in cardio-ankle vascular index by long-term continuous positive airway pressure therapy for obstructive sleep apnea. J Cardiol 2011; 58: 74-82.

[87] Park JS, Nam JS, Cho MH, et al. Insulin resistance independently influences arterial stiffness in normoglycemic normotensive postmenopausal women. Menopause 2010; 17: 779-84.

[88] Lebrun CE, van der Schouw YT, Bak AA, et al. Arterial stiffness in postmenopausal women: determinants of pulse wave velocity. $\mathrm{J}$ Hypertens 2002; 20: 2165-72.

[89] Figueroa A, Vicil F, Sanchez-Gonzalez MA, et al. Effects of diet and/or low-intensity resistance exercise training on arterial stiffness, adiposity, and lean mass in obese postmenopausal women. Am J Hypertens 2013; 26: 416-23.

[90] Rizzo MR, Leo S, De Franciscis P, Colacurci N, Paolisso G. Shortterm effects of low-dose estrogen/drospirenone vs low-dose estrogen/dydrogesterone on glycemic fluctuations in postmenopausal women with metabolic syndrome. Age (Dordr). 2013 Jul 7. [Epub ahead of print]

[91] Simkova A, Bulas J, Balogova S, et al. Metabolic syndrome and its effect on aortic stiffness in premenopausal women. Bratisl Lek Listy 2013; 114: 279-82.

[92] 92 Agarwal N, Rice SP, Bolusani H, et al. Metformin reduces arterial stiffness and improves endothelial function in young women with polycystic ovary syndrome: a randomized, placebocontrolled, crossover trial. J Clin Endocrinol Metab 2010; 95: 72230 .

[93] Soares GM, Vieira CS, Martins WP, et al. Increased arterial stiffness in nonobese women with polycystic ovary syndrome (PCOS) without comorbidities: one more characteristic inherent to the syndrome? Clin Endocrinol (Oxf) 2009; 71: 406-11.

[94] Kaya MG, Calapkorur B, Karaca Z, et al. The effects of treatment with drospirenone/ethinyl oestradiol alone or in combination with metformin on elastic properties of aorta in women with polycystic ovary syndrome. Clin Endocrinol (Oxf) 2012; 77: 885-92. 
[95] Khoshdel AR, Carney SL, Gillies A. Circulatory syndrome: an evolution of the metabolic syndrome concept! Curr Cardiol Rev 2012; 8: 68-76.

[96] Devaraj S, Rosenson RS, Jialal I. Metabolic syndrome: an appraisal of the pro-inflammatory and procoagulant status. Endocrinol Metab Clin North Am 2004; 33: 431-53.

[97] Nieuwdorp M, Stroes ES, Meijers JC, Büller H. Hypercoagulability in the metabolic syndrome. Curr Opin Pharmacol 2005; 5: 155-9.

[98] Sagastagoitia JD, Sáez Y, Vacas M, et al. Association between inflammation, lipid and hemostatic factors in patients with stable angina. Thromb Res 2007; 120: 53-9.

[99] Aso Y, Wakabayashi S, Terasawa T, et al. Elevation of serum high molecular weight adiponectin in patients with Type 2 diabetes and orthostatic hypotension: association with arterial stiffness and hypercoagulability. Diabet Med 2012; 29: 80-7.
[100] Robinson K, Prins J, Venkatesh B. Clinical review: adiponectin biology and its role in inflammation and critical illness. Crit Care 2011; 15: 221-9.

[101] Panagiotakos DB, Pitsavos C, Chrysohoou C, Kavouras S, Stefanadis C; ATTICA Study. The associations between leisure-time physical activity and inflammatory and coagulation markers related to cardiovascular disease: the ATTICA Study. Prev Med 2005; 40: $432-7$.

[102] Athyros VG, Mikhailidis DP, Papageorgiou AA, et al. Effect of statins and ACE inhibitors alone and in combination on clinical outcome in patients with coronary heart disease. J Hum Hypertens 2004; 18: 781-8.

[103] Athyros VG, Mikhailidis DP, Papageorgiou AA, et al. Effect of statins and aspirin alone and in combination on clinical outcome in dyslipidaemic patients with coronary heart disease. A subgroup analysis of the GREACE study. Platelets 2005; 16: 65-71.

Received: August 10, 2013

Revised: August 19, 2013

Accepted: August 19, 2013

(C) Athyros et al.; Licensee Bentham Open.

This is an open access article licensed under the terms of the Creative Commons Attribution Non-Commercial License (http://creativecommons.org/licenses/by-nc/3.0/) which permits unrestricted, non-commercial use, distribution and reproduction in any medium, provided the work is properly cited. 